\title{
Improving the monacolin $\mathrm{K}$ to citrinin production ratio in red yeast rice by an X-ray-induced mutant strain of Monascus purpureus
}

\author{
Apinun Kanpienguai ${ }^{1,2}$, Rapeepun Mahawan ${ }^{1,3}$, Prodpran Pengnoi ${ }^{3}$, \\ SAISAMORN LUMYONG ${ }^{3}$, CHARTCHAI KHANONGNUCH ${ }^{1 *}$ \\ ${ }^{1}$ Division of Biotechnology, Faculty of Agro-Industry, Chiang Mai University, Chiang Mai, Thailand \\ ${ }^{2}$ Department of Chemistry, Faculty of Science, Chiang Mai University, Chiang Mai, Thailand \\ ${ }^{3}$ Department of Biology, Faculty of Science, Chiang Mai University, Chiang Mai, Thailand
}

\begin{abstract}
Red yeast rice (RYR), which is fermented by Monascus purpureus CMU002U, contains high amounts of monacolin $\mathrm{K}$ - a secondary metabolite with health benefits that has consequently gained interest in research. Although monacolin $\mathrm{K}$ is recognized as an anti-hypercholesterolemic agent, citrinin is a toxic substance that is simultaneously synthesized during RYR fermentation. An X-ray mutagenesis of $M$. purpureus CMU002U was conducted to achieve a lower-citrinin-producing strain with an improvement of monacolin $\mathrm{K}$ to citrinin $(\mathrm{M} / \mathrm{C}) \mathrm{ratio}$. Among the selected mutants, CMU002UXX-32-44 was the strain having the most potential with regard to the lowest level of citrinin production capability, along with an improved M/C ratio (from 1460 to 1790 when compared with the parental strain). Furthermore, the medium and conditions for RYR fermentation using glutinous rice as the substrate were statistically optimized. The Plackett and Burman design revealed that moisture content and incubation time were the most significant factors enhancing monacolin $\mathrm{K}$ production, besides the addition of alternative mineral and nitrogen sources. After the application of a response surface methodology, the maximum monacolin $\mathrm{K}$ concentration of $6428 \mathrm{mg} / \mathrm{kg}$ was predicted and successfully produced with $90 \%$ validation when the moisture content and incubation time were set to $75 \%$ and 38 days, respectively - leading to a 5.1 -fold increase in monacolin K. Under these conditions, RYR was contaminated with citrinin levels acceptable to the international standards for citrinin in food supplements, whereas the $\mathrm{M} / \mathrm{C}$ ratio was improved to 3990 . Therefore, this mutant displayed a strong potential for use at the industrial scale.
\end{abstract}

Key words: citrinin, Monascus purpureus, monacolin K, X-ray mutagenesis

\section{Introduction}

Red yeast rice (RYR) is a fermented product obtained from the incubation of rice substrate with Monascus spp., and has been traditionally used for the coloring, flavoring, and preservation of foods in East Asia for more than 1000 years (Li et al., 2013; Mohan Kumari et al., 2009). RYR is rich in many useful compounds such as monacolins, gamma-aminobutyric acid (GABA), glucosamine, lecithin, flavonoids, and dimerumic acid that are known to be beneficial for health (Chairote et al., 2008; Mohan Kumari et al., 2009; Patakova et al., 2016). The use of RYR has become very common in alternative therapeutic regimens for hyperlipidermia because it contains the useful compound monacolin $\mathrm{K}$, also known as lovastatin or mevinolin; monacolin $\mathrm{K}$ is known to be a high-potential competitive inhibitor of 3-hydroxy-3-methyl glutaryl-coenzyme A (HMG-CoA) reductase. Monacolin $\mathrm{K}$ catalyzes the reduction of HMG-CoA to mevalonate during cholesterol biosynthesis (Chairote et al., 2008; Panda et al., 2010), and has been reported to have special effects on the reduction of blood-lipid levels in humans and animals (Liao et al., 2014). Thus, it has po-

\footnotetext{
* Corresponding author: Division of Biotechnology, Faculty of Agro-Industry, Chiang Mai University, Chiang Mai 50100, Thailand; e-mail: chartchai.k@cmu.ac.th
} 
tential for use in cholesterol-lowering and dietary supplement products (Wang et al., 2004). Although RYR is an important food ingredient with various potential therapeutic properties, some controversy exists over the use of RYR because of the production of citrinin - a mycotoxin that causes nephrotoxic and hepatotoxic reactions in the mammalian system (Kalaivani and Rajasekaran, 2014). Because citrinin and monacolin $\mathrm{K}$ are both produced by the polyketide biosynthetic pathway, there is a high level of concern about safety pertaining to the development of RYR as a functional food ingredient and its use in pharmaceutical products. Several strategies have been used to achieve high monacolin $\mathrm{K}$ production and citrinin reduction that involve determining the optimal medium conditions (Prajapati et al., 2014), a fermentation process (Feng et al., 2014), and strain improvement of Monascus spp. (Kalaivani and Rajasekaran, 2014; Sun et al., 2011), compared to RYR production with high monacolin $\mathrm{K}$ and low citrinin concentrations (Jirasatid et al., 2013; Wang et al., 2003). With regard to achieving a promising approach, this paper describes the strain improvement of Monascus purpureus by X-ray - induced-mutation for RYR fermentation with a resultant reduction in the citrinin content and an improvement in the ratio of monacolin $\mathrm{K}$ to citrinin production (the $\mathrm{M} / \mathrm{C}$ ratio) in RYR. Moreover, the simplest medium and conditions for red mold rice fermentation were established by a statistical optimization approach to elevate the $\mathrm{M} / \mathrm{C}$ ratio.

\section{Materials and methods}

\section{Microorganisms and culture conditions}

M. purpureus CMU002U was obtained from the Sustainable Development of the Biological Resources Laboratory, the Faculty of Science, Chiang Mai University, Chiang Mai, Thailand, and used for the production of monacolin K. M. purpureus was grown on Potato dextrose agar (PDA) at $30^{\circ} \mathrm{C}$ for 7 days. Bacillus subtilis TISTR 1460 was obtained from the Thailand Institute of Scientific and Technological Research (TISTR), Bangkok, Thailand and grown on nutrient agar (NA) at $37^{\circ} \mathrm{C}$ for $18-24 \mathrm{~h}$.

\section{Chemicals}

Standard monacolin K and citrinin were of analytical grade and purchased from Sigma-Aldrich (St. Louis, MO,
USA). High-performance liquid chromatography (HPLC)grade acetonitrile and ethanol were purchased from Merck (Darmstadt, Germany). Analytical grade acetone and ethyl acetate were purchased from RCI Labscan Ltd. (Pathumwan, Bangkok, Thailand). Potatoes dextrose broth (PDB) and Nutrient broth (NB) were purchased from Difco (Detroit, MI, USA). Reagent-grade trifluoroacetic acid was purchased from Sigma-Aldrich (St. Louis, MO, USA), and the phosphoric acid was purchased from Merck (Darmstadt, Germany).

\section{Induction of mutagenesis by $\mathrm{X}$-ray irradiation}

M. purpureus CMU002U was grown on PDA at $30^{\circ} \mathrm{C}$ for 7 days. For this, the PDA plate was submerged in $10 \mathrm{ml}$ sterile water, and the spores were brought into suspensions that were then diluted to $10^{6}$ spores $/ \mathrm{ml}$ for X-ray irradiation. The survival rate of $M$. purpureus CMU002U against X-ray irradiation was investigated using the KXO-1 5R X-ray generator (Toshiba Medical Systems Corporation, Tochigi, Japan) at the conditions of 40-cm distance, a voltage of $50 \mathrm{kV}$, and $100 \mathrm{~mA}$ current. The exposure time was varied from 0 to $16 \mathrm{~s}$. Samples were serially diluted for viable cell counting on a PDA plate by using the spread-plate technique. With regard to the $\mathrm{D}_{10}$ values (Moeller et al., 2014), the exposure time required for $90 \%$ reduction was determined using the survival data collected during the treatment. The survival percentage was calculated by dividing the viable cell count after X-ray irradiation by the initial viable cell count.

\section{Screening and isolation of low-citrinin-producing mutants of M. purpureus CMU002U}

Colonies of X-ray-induced M. purpureus CMU002U were isolated for bioassay in the primary screening of citrinin production according to a previously described protocol (Wang et al., 2004), but with some modifications. Briefly, an aliquot $(100 \mu \mathrm{l})$ of 24 -h culture of $B$. subtilis TISTR 1460 was spread on a PDA plate. The isolated colony of X-ray-induced $M$. purpureusCMU002U was picked up and transferred to the PDA with $B$. subtilis TISTR 1460 to observe whether an inhibition zone was formed after incubation at $30^{\circ} \mathrm{C}$ for 3 days whereas the rest of the colony was replicated on the PDA. M. purpureus strains with either low levels or no inhibition zones were selected for RYR fermentation and further confirmation of monacolin $\mathrm{K}$ and citrinin production. 
Table 1. Experimental design and response in Plackett-Burman design

\begin{tabular}{c|c|c|c|c|c|c|c|c}
\hline Treatment & $\begin{array}{c}\text { Rice } \\
{[\mathrm{g}]}\end{array}$ & $\begin{array}{c}\text { Moisture } \\
\text { content } \\
{[\%]}\end{array}$ & $\begin{array}{c}\text { Incubation } \\
\text { time } \\
\text { [days] }\end{array}$ & $\begin{array}{c}\text { Inoculum } \\
{[\%]}\end{array}$ & $\begin{array}{c}\mathrm{NH}_{4} \mathrm{Cl} \\
{[\mathrm{mg} / \mathrm{g} \text { substrate] }}\end{array}$ & $\begin{array}{c}\mathrm{MgSO}_{4} \cdot 7 \mathrm{H}_{2} \mathrm{O} \\
{[\mathrm{mg} / \mathrm{g} \text { substrate] }}\end{array}$ & $\begin{array}{c}\text { Predicted } \\
{[\mathrm{mg} / \mathrm{kg}]}\end{array}$ & $\begin{array}{c}\text { Experimental } \\
{[\mathrm{mg} / \mathrm{kg}]}\end{array}$ \\
\hline 1 & $30(+1)$ & $70(+1)$ & $7(-1)$ & $10(+1)$ & $52(+1)$ & $2.6(+1)$ & 1036.9 & 1365.4 \\
\hline 2 & $15(-1)$ & $70(+1)$ & $14(+1)$ & $3(-1)$ & $52(+1)$ & $2.6(+1)$ & 1641.8 & 1509.8 \\
\hline 3 & $30(+1)$ & $50(-1)$ & $14(+1)$ & $10(+1)$ & $4(-1)$ & $2.6(+1)$ & 1097.6 & 905.9 \\
\hline 4 & $15(-1)$ & $70(+1)$ & $7(-1)$ & $10(+1)$ & $52(+1)$ & $0.2(-1)$ & 1288.1 & 1123.6 \\
\hline 5 & $15(-1)$ & $50(-1)$ & $14(+1)$ & $3(-1)$ & $52(+1)$ & $2.6(+1)$ & 636.2 & 768.2 \\
\hline 6 & $15(-1)$ & $50(-1)$ & $7(-1)$ & $10(+1)$ & $4(-1)$ & $2.6(+1)$ & 92.5 & 98.5 \\
\hline 7 & $30(+1)$ & $50(-1)$ & $7(-1)$ & $3(-1)$ & $52(+1)$ & $0.2(-1)$ & 541.4 & 581.5 \\
\hline 8 & $30(+1)$ & $70(+1)$ & $7(-1)$ & $3(-1)$ & $4(-1)$ & $2.6(+1)$ & 1071.9 & 644.2 \\
\hline 9 & $30(+1)$ & $70(+1)$ & $14(+1)$ & $3(-1)$ & $4(-1)$ & $0.2(-1)$ & 2613.3 & 3068.2 \\
\hline 10 & $15(-1)$ & $70(+1)$ & $14(+1)$ & $10(+1)$ & $4(-1)$ & $0.2(-1)$ & 2354.5 & 2295.4 \\
\hline 11 & $30(+1)$ & $50(-1)$ & $14(+1)$ & $10(+1)$ & $52(+1)$ & $0.2(-1)$ & 1572.7 & 1368.6 \\
\hline 12 & $15(-1)$ & $50(-1)$ & $7(-1)$ & $3(-1)$ & $4(-1)$ & $0.2(-1)$ & 317.6 & 250.3 \\
\hline 13 & $22.5(0)$ & $60(0)$ & $10.5(0)$ & $6.5(0)$ & $28(0)$ & $1.4(0)$ & 1842.8 & 1807.3 \\
\hline 14 & $22.5(0)$ & $60(0)$ & $10.5(0)$ & $6.5(0)$ & $28(0)$ & $1.4(0)$ & 1842.8 & 1786.5 \\
\hline 15 & $22.5(0)$ & $60(0)$ & $10.5(0)$ & $6.5(0)$ & $28(0)$ & $1.4(0)$ & 1842.8 & 1934.6 \\
\hline
\end{tabular}

\section{Solid-state fermentation of RYR}

The solid-state fermentation (SSF) of RYR was conducted using glutinous rice (Oryza sativa L. var. Niaw San Pah Tawng) as the substrate, according to a previously described protocol (Kanpiengjai et al., 2016). M. purpureus was pre-cultured in a 50-ml PDB on a 150 -rpm rotary shaker at $30^{\circ} \mathrm{C}$ for 3 days to achieve $10^{6}$ spores $/ \mathrm{ml}$. We transferred $5 \%(\mathrm{v} / \mathrm{w})$ of the fungal spore suspension onto the solid medium, which was then statically incubated at $30^{\circ} \mathrm{C}$ for 14 days. The RYR thus obtained was harvested and dried at $60^{\circ} \mathrm{C}$ overnight for further quantitative analysis of monacolin $\mathrm{K}$ and citrinin contents.

\section{Screening of the most significant medium components using the Plackett-Burman design}

The Plackett-Burman design (PBD) method is an efficient method of optimization and was used to screen the most significant medium components for monacolin $\mathrm{K}$ production by the X-ray mutant, $M$. purpureus $\mathrm{CMU}$ 002UXX-32-44. Glutinous rice, $\mathrm{NH}_{4} \mathrm{Cl}, \mathrm{MgSO}_{4}$, moisture content, incubation time, and inoculum were all tested. All factors were prepared at two levels: -1 for low level and +1 for high level. The Design Expert software Version 7.0.0 (Stat-Ease, MN) was used for the experi- mental design and the analysis of variance (ANOVA). In this experiment, PBD included 12 runs of various combinations of the assessed factors, together with three runs of the center-point for monacolin $\mathrm{K}$ production (Table 1). All runs were conducted in triplicate in a 250-ml Erlenmeyer flask. A statistical confidence level of more than $95 \%$ was accepted in this experiment. Factors with the most significant effects on enhancing of monacolin $\mathrm{K}$ production were included in the optimization experiments.

\section{Optimization using central composite rotatable design (CCRD)}

The central composite rotatable design (CCRD) one of the designs in response surface methodology (RSM) - was applied to find the optimum level of the aforementioned significant factors for maximum monacolin $\mathrm{K}$ production. The two selected significant factors predicted by the PBD method were moisture content $\left(\mathrm{X}_{1}\right)$ and incubation time $\left(\mathrm{X}_{2}\right)$. Design Expert software Version 7.0.0 (Stat-Ease, MN) was used for the experimental design and the regression analysis. With regard to the two factors, the experimental design included 13 runs (comprising four factorial points, four axial star points, and five center-points), and fermentation was car- 
Table 2. Full factorial central rotatable composite design matrix of moisture content and incubation time in actual and coded values with the experimental and predicted values

\begin{tabular}{c|c|c|c|c}
\hline Treatment & $\begin{array}{c}\text { Moisture content } \\
{[\%]}\end{array}$ & $\begin{array}{c}\text { Incubation time } \\
{[\text { days] }}\end{array}$ & $\begin{array}{c}\text { Predicted } \\
{[\mathrm{mg} / \mathrm{kg}]}\end{array}$ & $\begin{array}{c}\text { Experimental } \\
{[\mathrm{mg} / \mathrm{kg}]}\end{array}$ \\
\hline 1 & $60(-1)$ & $14(-1)$ & 2035.8 & 2040.4 \\
\hline 2 & $85(+1)$ & $14(-1)$ & 1991.8 & 2007.9 \\
\hline 3 & $60(-1)$ & $60(+1)$ & 1162.4 & 1153.6 \\
\hline 4 & $85(+1)$ & $60(+1)$ & 3427.1 & 3429.8 \\
\hline 5 & $54.82(-\alpha)$ & $37(0)$ & 2165.8 & 2170.3 \\
\hline 6 & $90.18(+\alpha)$ & $37(0)$ & 3736.2 & 3724.4 \\
\hline 7 & $72.5(0)$ & $4.47(-\alpha)$ & 1158.9 & 1145.7 \\
\hline 8 & $72.5(0)$ & $69.53(+\alpha)$ & 1556.2 & 1562.1 \\
\hline 9 & $72.5(0)$ & $37(0)$ & 5796.9 & 6238.2 \\
\hline 10 & $72.5(0)$ & $37(0)$ & 5796.9 & 5775.3 \\
\hline 11 & $72.5(0)$ & $37(0)$ & 5796.9 & 5659.8 \\
\hline 12 & $72.5(0)$ & $37(0)$ & 5796.9 & 5723.5 \\
\hline 13 & $72.5(0)$ & $37(0)$ & 5796.9 & 5588.10 \\
\hline
\end{tabular}

ried out separately for each run in triplicate. The experimental monacolin $\mathrm{K}$ values were taken as the response and used to fit a second-order polynomial Equation (1) (Table 2).

$$
Y=\beta_{0}+\sum \beta_{i} x_{i}+\sum \beta_{i i} x_{i}^{2}+\sum \beta_{i j} x_{i} x_{j}
$$

where $Y$ represents the predicted response factor, $\beta_{0}$ is the constant coefficient, $\beta_{i}$ is representative of the linear coefficients, $\beta_{i j}$ represents the second-order interaction coefficients, $\beta_{i i}$ are the quadratic coefficients of the model, and $X_{i} X_{j}$ represent independent factors in terms of the actual values. ANOVA was conducted, and the response surface curves were plotted. Values of "Prob> $F$ " that were less than 0.05 indicated that the model terms were significant. The lack-of-fit $F$-value was not significantly relative to the pure errors, and it was thus considered a good model. The statistical model was validated with respect to the maximum monacolin $\mathrm{K}$ production when optimal levels of glutinous rice and incubation time were applied.

\section{Extraction and quantitative analysis of monacolin $K$ and citrinin}

Monacolin K and citrinin were extracted from RYR, and quantitative analysis was conducted using the previous protocols (Kanpiengjai et al., 2016). The ratio of monacolin $\mathrm{K}$ to citrinin production was calculated by di- viding the monacolin $\mathrm{K}$ content by the citrinin content (both in $\mathrm{mg} / \mathrm{kg}$ ).

\section{Results and discussion}

\section{Optimal X-ray irradiation conditions}

$\mathrm{X}$-ray is a type of ionizing radiation that is used to introduce random mutations. It has the advantages of deep penetration and rapid induction of various mutations when compared with chemical-induced mutation and non-ionizing radiation. To achieve a high probability of mutation and to avoid extensive radiation damages, as well as to minimize side effects (Ottenheim et al., 2015), a spore suspension was used for X-ray irradiation instead of mycelia. The X-ray mutagenesis of $M$. purpureus CMU002U was carried out and the number of viable cells and the percentage of survival rates were determined and expressed in terms of the time of exposure to X-ray irradiation. The survival rate of $M$. purpureus CMU002U was dramatically decreased with an increase in the X-ray dosage. This was because of the lethal degree of DNA damage associated with X-ray irradiation (Gopinath et al., 2009). However, recent reports have revealed that the survival of many organisms is associated with the level of the oxidative protein damage that occurs during the irradiation process. This damage limits the functionality and efficiency of enzymes, parti- 


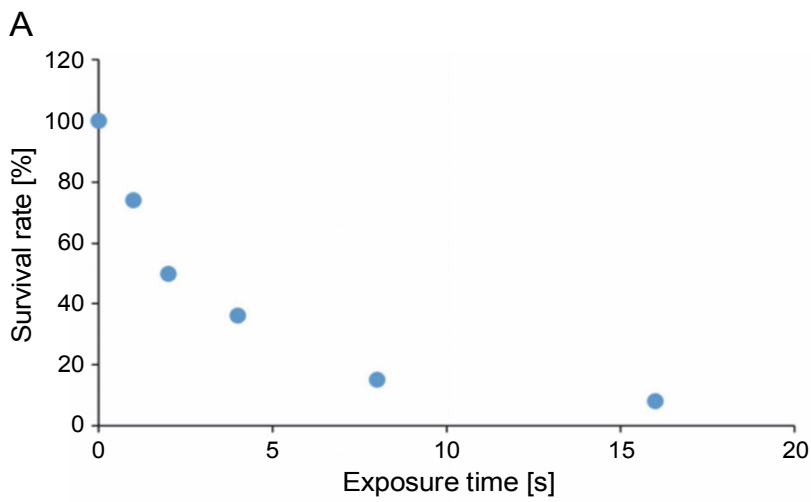

B

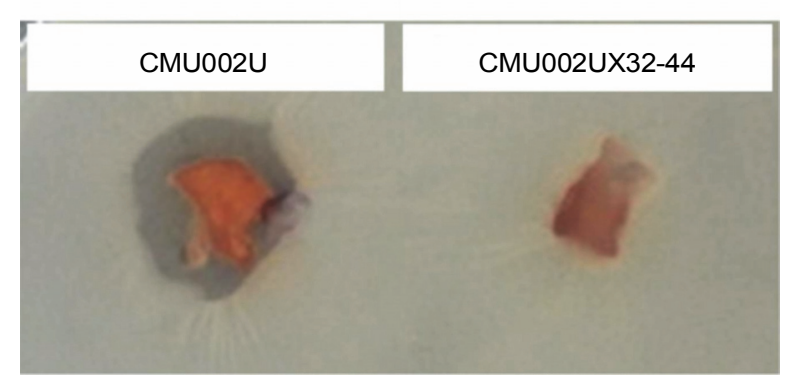

Fig. 1. The effect of various X-ray irradiation doses on viable cells of $M$. purpureus CMU002U.A) formation of the inhibition zone against $B$. subtilis TISTR1460 of $M$.purpureus CMU002U on the PDA plate (left), B) when compared with M. purpureus CMU002UXX-32-44 (right)

cularly those required in the repair and replication of DNA (Daly, 2012). With a $\mathrm{D}_{10}$ value of exposure time between 8 and $16 \mathrm{~s}, M$. purpureus CMU002U was resistant to the X-ray exposure and survived with an average $90 \%$ cell death (Fig. 1A); thus this condition was selected as the effective dosage for the induction of mutation for further experimentation.

\section{Mutant screening}

The surviving colonies of $M$. purpureus CMU002U were picked up and transferred to the PDA plates, and those plates with $B$. subtilis TISTR 1460 cultures were used for the bioassay test via the replica plating technique. The inhibition zone is determined through a simple and quick selection method for detecting $\mathrm{Mo}$ nascus sp. with low citrinin production levels, based on citrinin's antibacterial activity against $B$. subtilis. Monascus strains capable of citrinin production form an inhibition zone surrounding the colony against $B$. subtilis. The size of the inhibition zone is proportional to the citrinin content (Wang et al., 2004). After the bioassay test, five strains of mutants (CMU002UX-09, CMU002
UX32, CMU002UX81, CMU002UX119, and CMU 002UX -161) showed no inhibition zone against $B$. subtilis TISTR 1460 (Fig. 1B) and, thus, were chosen for further tests. M. purpureus CMU002U, the parental strain, produced $11267 \mathrm{mg} / \mathrm{kg}$ monacolin $\mathrm{K}$ and $7.7 \mathrm{mg} / \mathrm{kg}$ citrinin - significantly higher values than those produced by the selected mutants (Table 3) - and were found to be relative to the ratio of monacolin $\mathrm{K}$ to citrinin production $(\mathrm{M} / \mathrm{C}$ ratio) of 1460. All mutants produced lower levels of citrinin than the parental strain, which agrees with the results from the bioassay test. In addition, the $\mathrm{M} / \mathrm{C}$ ratio obtained from the mutants was not particularly improved from the parental strain due to a marked decline in monacolin $\mathrm{K}$ production - with the exception of $M$. purpureus CMU002UX-32, which retained the lowest citrinin production $(2.4 \mathrm{mg} / \mathrm{kg})$ among the mutant strains and exhibited a slightly higher $\mathrm{M} / \mathrm{C}$ ratio compared to the parental strain.

In this work, chemical mutagens and UV radiation were applied to treat $M$. purpureus for strain improvement, as also reported previously (Jia et al., 2010). Interestingly, fast neutron and X-ray irradiation have previously been used to effectively enhance the pigment production capability of the $M$. purpureus Went strain (Wong and Bau, 1977). Although the strain was improved with a twofold increase in pigment production, a higher antibacterial activity was also observed as was the presence of monascidin A, which was further characterized as citrinin (Blanc et al., 1995). With regard to the polyketide biosynthesis pathway, it is known, in principle, that the monacolins and citrinin pigments are produced by the same route; thus, a random mutagenesis is slightly difficult to successfully induce (Wang et al., 2004). To further improve the $\mathrm{M} / \mathrm{C}$ ratio of a mutant strain with a low citrinin production, $M$. purpureus CMU002UX-32 was selected for the secondary process of X-ray irradiation. By using the same X-ray irradiation conditions and the screening protocol, we found that $M$. purpureus CMU002 UXX-32-44 produced $1250 \mathrm{mg} / \mathrm{kg}$ monacolin $\mathrm{K}$ and $0.7 \mathrm{mg} / \mathrm{kg}$ citrinin, resulting in an $\mathrm{M} / \mathrm{C}$ ratio of 1790 (Table 3). This was acceptable for optimization using a statistical approach in terms of the $\mathrm{M} / \mathrm{C}$ ratio and citrinin production. Moreover, this mutant retained the $\mathrm{M} / \mathrm{C}$ ratio for at least 10 generations (data not published).

\section{Plackett-Burman design}

Thailand has been globally ranked as one of the largest rice producers, and more than $50 \%$ of its rice pro- 
Table 3. Summary for monacolin $\mathrm{K}$ and citrinin production, and the $\mathrm{M} / \mathrm{C}$ ratio obtained from $\mathrm{RYR}$ produced by various mutant strains

\begin{tabular}{|c|c|c|c|}
\hline Mutant & $\begin{array}{c}\text { Monacolin } \mathrm{K} \\
{[\mathrm{mg} / \mathrm{kg}]}\end{array}$ & $\begin{array}{l}\text { Citrinin } \\
{[\mathrm{mg} / \mathrm{kg}]}\end{array}$ & $\begin{array}{c}\text { Monacolin } \mathrm{K} \\
\text { to citrinin ratio }\end{array}$ \\
\hline \multicolumn{4}{|c|}{$1^{\text {st }}$ mutation } \\
\hline $002 \mathrm{U}$ & $11267 \pm 278$ & $7.7 \pm 0.2$ & $1460 \pm 52$ \\
\hline 002UX-09 & $2893 \pm 112$ & $2.6 \pm 0.5$ & $1100 \pm 220$ \\
\hline 002UX-32 & $3830 \pm 88$ & $2.3 \pm 0.03$ & $1670 \pm 44$ \\
\hline 002UX-81 & $3235 \pm 48$ & $3.1 \pm 0.05$ & $1040 \pm 23$ \\
\hline 002UX-119 & $2894 \pm 151$ & $2.7 \pm 0.08$ & $1070 \pm 64$ \\
\hline 002UX-161 & $2806 \pm 77$ & $2.4 \pm 0.1$ & $1170 \pm 58$ \\
\hline \multicolumn{4}{|c|}{$2^{\text {nd }}$ mutation } \\
\hline 002UXX-32-05 & $1052 \pm 21$ & $1.0 \pm 0.02$ & $1050 \pm 30$ \\
\hline 002UXX-32-44 & $1250 \pm 10$ & $0.7 \pm 0.03$ & $1790 \pm 78$ \\
\hline 002UXX-32-112 & $975 \pm 85$ & $0.9 \pm 0.01$ & $1080 \pm 95$ \\
\hline 002UXX-32-159 & $1009 \pm 43$ & $0.9 \pm 0.02$ & $1120 \pm 54$ \\
\hline 002UXX-32-227 & $1024 \pm 102$ & $1.1 \pm 0.05$ & $900 \pm 100$ \\
\hline 002UXX-32-314 & $995 \pm 116$ & $0.9 \pm 0.02$ & $1100 \pm 130$ \\
\hline 002UXX-32-427 & $1102 \pm 76$ & $1.2 \pm 0.05$ & $920 \pm 74$ \\
\hline
\end{tabular}

duction is utilized for domestic consumption (Kanpiengjai et al., 2014). Thus, rice is the most abundant crop in Thailand and can be promoted as a material for the production of value-added products. Non-glutinous rice and glutinous rice are the two main kinds of rice grown and consumed by most Thai people. These possess significantly different amounts of amylose and amylopectin that affect the monacolin K content of RYR (Chairote et al., 2008). For most $M$. purpureus strains, glutinous rice, as a solid substrate, has contributed to higher monacolin $\mathrm{K}$ concentrations of RYR than the non-glutinous rice (Chairote et al., 2008). Because San-Pah-Tawng glutinous rice has been developed and promoted to be specifically cultivated in northern Thailand, it is abundant in this particular area. Thus, utilization of San-Pah-Tawng glutinous rice for value-added product production has also been promoted. In addition, with regard to the reasons given by previous research studies (Chairote et al., 2008) together with our previous data (data not shown), San-Pah-Tawng glutinous rice was selected to establish a simple medium and effective composition for RYR production. It is known that monacolin $\mathrm{K}$ production is dependent not only on the substrates provided but also on the culture conditions because there have been va- rious bioprocess improvements and medium optimization techniques attempting to achieve a high monacolin $\mathrm{K}$ production with low citrinin concentrations (Chen and Hu, 2005; Jirasatid et al., 2013; Miyake et al., 2006). Therefore, inoculum size, incubation time, and moisture content were included in the PBD. $M$. purpureus $\mathrm{CMU}$ 002UXX-32-44 produced monacolin $\mathrm{K}$, varying from 440 to $3000 \mathrm{mg} / \mathrm{kg}$, across 13 different media and conditions, thereby indicating an improvement in monacolin K production (Table 1). According to the data analysis (Table 4), the experimental monacolin $\mathrm{K}$ fitted with the linear model was recorded at $P<0.05$ and $R^{2}$ of 0.90 . Moisture content and incubation time were the most effective factors in enhancing monacolin $\mathrm{K}$ production as opposed to $\mathrm{MgSO}_{4}$, which showed a strongly negative effect on its production. Moreover, $\mathrm{NH}_{4} \mathrm{Cl}$ was identified as a factor that decreased the amount of monacolin $\mathrm{K}$ present in RYR at a higher concentration.

The initial moisture content is one of the key factors for regulating fungal growth, enzyme activity, and metabolite production in SSF (Babitha et al., 2007). The optimum moisture content for the production of monacolin $\mathrm{K}$ using corncobs as a solid substrate was in the range of $60-80 \%$ and was found to promote amylolytic enzyme 
Table 4. ANOVA analysis Data of six factors on production of monacolin $\mathrm{K}$ in $\mathrm{PBD}$

\begin{tabular}{l|c|c|c|c|c|c}
\hline \multirow{2}{*}{ Source } & $\begin{array}{c}\text { Coefficient } \\
\text { estimate }\end{array}$ & Sum of squares & df & Mean square & $F$-value & $P$-value \\
\cline { 4 - 7 } Model & 1164.97 & $7.18 \times 10^{6}$ & 6 & $1.20 \times 10^{6}$ & 11.24 & 0.0027 \\
\hline A - rice & 157.33 & $2.97 \times 10^{5}$ & 1 & $2.97 \times 10^{5}$ & 2.79 & 0.1388 \\
\hline $\mathrm{B}-$ moisture & 502.80 & $3.03 \times 10^{6}$ & 1 & $3.03 \times 10^{6}$ & 28.49 & $0.0011^{*}$ \\
\hline $\mathrm{C}-$ incubation & 487.72 & $2.85 \times 10^{6}$ & 1 & $2.85 \times 10^{6}$ & 26.81 & $0.0013^{*}$ \\
\hline $\mathrm{D}-$ inoculum & 27.93 & $9.36 \times 10^{3}$ & 1 & $9.36 \times 10^{3}$ & 0.088 & 0.7754 \\
\hline $\mathrm{E}-\mathrm{NH}_{4} \mathrm{Cl}$ & -45.45 & $2.48 \times 10^{4}$ & 1 & $2.48 \times 10^{4}$ & 0.23 & 0.6442 \\
\hline $\mathrm{F}-\mathrm{MgSO}_{4}$ & -282.97 & $9.61 \times 10^{5}$ & 1 & $9.61 \times 10^{5}$ & 9.02 & $0.0198^{*}$ \\
\hline Curvature & 677.83 & $1.10 \times 10^{6}$ & 1 & $1.10 \times 10^{6}$ & 10.36 & 0.0147 \\
\hline Residual & & $7.45 \times 10^{5}$ & 7 & $1.06 \times 10^{5}$ & & \\
\hline Lack of fit & & $7.32 \times 10^{5}$ & 5 & $1.81 \times 10^{5}$ & 22.79 & 0.0426 \\
\hline Pure error & & $1.28 \times 10^{4}$ & 2 & $6.42 \times 10^{3}$ & & \\
\hline Cor total & & $9.03 \times 10^{6}$ & 14 & & & \\
\hline
\end{tabular}

Standard deviation - 326.3, mean - 1300.53, coefficient of variance (CV\%) $-25.09, R^{2}-0.9060$, adjusted $R^{2}-0.8029$

Table 5. ANOVA analysis of moisture content and incubation time for monacolin $\mathrm{K}$ production after being fitted with response surface quadratic model

\begin{tabular}{l|c|c|c|c|c|c}
\hline \multicolumn{1}{c|}{ Source } & $\begin{array}{c}\text { Coefficient } \\
\text { estimate }\end{array}$ & Sum of squares & $\mathrm{df}$ & Mean square & $F$-value & $P$-value \\
\cline { 4 - 7 } Model & 5796.98 & $4.73 \times 10^{7}$ & 5 & $9.46 \times 10^{6}$ & 251.22 & Prob $>F$ \\
\hline moisture & 555.19 & $2.47 \times 10^{6}$ & 1 & $2.47 \times 10^{6}$ & 65.45 & $<0.0001$ \\
\hline incubation & 140.50 & $1.58 \times 10^{5}$ & 1 & $1.58 \times 10^{5}$ & 4.19 & 0.0798 \\
\hline & 577.18 & $1.33 \times 10^{6}$ & 1 & $1.33 \times 10^{6}$ & 35.37 & 0.0006 \\
\hline & -1422.99 & $1.41 \times 10^{7}$ & 1 & $1.41 \times 10^{7}$ & 373.89 & $<0.0001$ \\
\hline Residual & -2219.71 & $3.42 \times 10^{7}$ & 1 & $3.42 \times 10^{7}$ & 909.77 & $<0.0001$ \\
\hline Lack of fit & & $2.64 \times 10^{5}$ & 7 & $3.77 \times 10^{4}$ & & \\
\hline Pure error & & 731.11 & 3 & 243.70 & $3.707 \times 10^{3}$ & 0.9996 \\
\hline Cor total & & $2.63 \times 10^{5}$ & 4 & $6.57 \times 10^{4}$ & & \\
\hline
\end{tabular}

Standard deviation - 194.10, mean - 3555.32, coefficient of variance (CV\%) - 5.46, $\mathrm{R}^{2}-0.9945$, adjusted $R^{2}-0.9905$

secretion by $M$. purpureus (Velmurugan et al., 2011). This finding was in an agreement with those of previous reports on the production of pigments and monacolin $\mathrm{K}$ on rice solid culture (Subsaendee et al., 2014). During the fermentation process, the moisture content of the medium changed due to the evaporation and microbial metabolic activities; this might have influenced the incubation time. For further experimentation, the opti- mum incubation time and moisture content were evaluated by the CCRD. $\mathrm{MgSO}_{4}$, exhibiting strong negative effects, has been excluded from the optimization process. Glutinous rice preparation in PDB and inoculum size were fixed at $30 \mathrm{~g}$ and $10 \%(\mathrm{v} / \mathrm{v})$, respectively, whereas $\mathrm{NH}_{4} \mathrm{Cl}$ was fixed at $4 \mathrm{mg} / \mathrm{g}$ substrate, based on PBD results. Therefore, the medium composition and conditions were simple and economical. In general, SSF 
and submerge fermentation were applied to achieve a high monacolin $\mathrm{K}$ content with a focus on certain levels of production of monacolin $\mathrm{K}$ rather than the traditional RYR. This study is among a few research studies on the optimization of the medium and the optimal conditions for RYR production with a high monacolin $\mathrm{K}$ content (Chen and Hu, 2005; Tsukahara et al., 2009).

\section{CCRD and model validation}

Five levels of the incubation time and moisture content were assigned with regard to CCRD, resulting in a total of 13 runs including five replicates of centerpoints. Experimental monacolin $\mathrm{K}$ contents (Table 2) varying from 1100 to $6200 \mathrm{mg} / \mathrm{kg}$ were fitted with the quadratic response surface model to generate a secondorder polynomial equation for the evaluation of the highest monacolin K production in terms of the actual value, as shown in Equation (2):

Monacolin $\mathrm{K}(\mathrm{mg} / \mathrm{kg})=-45487.78+1280.91 X_{i}+168.38 X_{j}$ $+2.03 X_{i} X_{j}-9.05 X_{i}^{2}-4.18 X_{j}^{2}$

where $X_{i}$ represents the incubation time (days) and $X_{j}$ represents the moisture content (percentages).

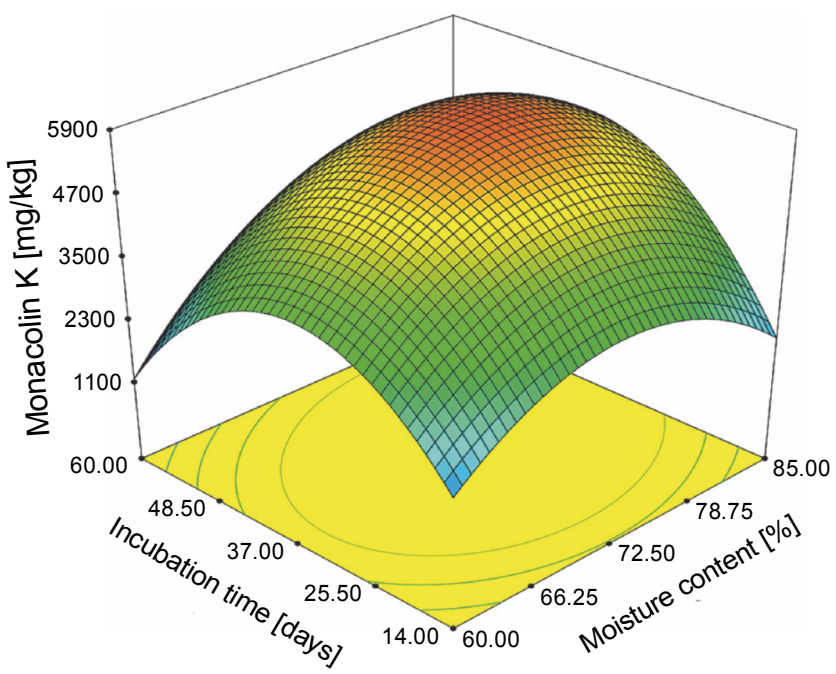

Fig. 2. The three-dimensional curve and a contour plot showing the effects of the moisture content and the incubation time on the production of monacolin $\mathrm{K}$ in RYR

The reliability of the two quadratic models could be explained by the ANOVA analysis (Table 5). In accordance with the significant $P$-value $(P=0.0014)$ of the estimated coefficient $\left(X_{i} X_{j}\right)$ obtained from the ANOVA,

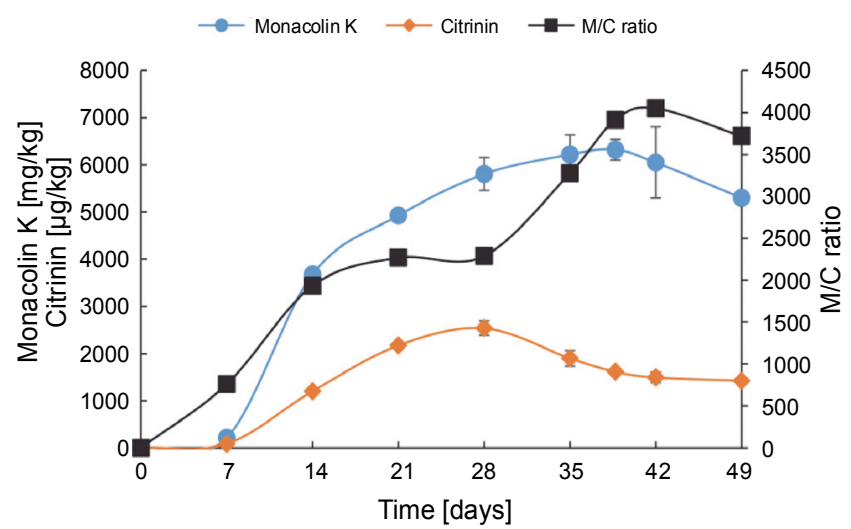

Fig. 3. The time course of monacolin $\mathrm{K}$ and citrinin concentrations and the $\mathrm{M} / \mathrm{C}$ ratio presented during RYR fermentation by M.purpureus CMU002UXX-32-44 under an optimized medium and conditions

a convex shape of the response surface plot (Fig. 2) indicated a positive interaction between the incubation time and the moisture content. The incubation time of 38.39 days and the moisture content of $75.09 \%$ were predicted as optimal conditions for the peak production of $5858 \mathrm{mg} / \mathrm{kg}$ monacolin K. Under these conditions, the experimental monacolin $\mathrm{K}$ yield was $6428 \mathrm{mg} / \mathrm{kg}$. Consequently, a $90 \%$ model validation and 5.1-fold increase in monacolin $\mathrm{K}$ production were achieved when compared with that from the non-optimized medium and conditions (Fig. 3). Considering the amount of citrinin after the optimization process, $M$. purpureus CMU002 UXX-32-44 produced $1.6 \mathrm{mg} / \mathrm{kg}$ citrinin, thus improving the $\mathrm{M} / \mathrm{C}$ ratio from 1790 to 3990 (Table 6). The monacolin $\mathrm{K}$ concentration obtained from the RYR in this study was higher than the concentration levels that were obtained in previous studies of monacolin $\mathrm{K}$ production (Chen and Hu, 2005; Jirasatid et al., 2013; Panda et al., 2010; Su et al., 2003; Tsukahara et al., 2009; Wang et al., 2003). The citrinin concentration was lower than the average level of citrinin contamination in various commercial Monascus products, especially with regard to the RYR present in Taiwan (Chen et al., 2016). In Taiwan, the regulatory limits of citrinin in RYR are 5 and $2 \mathrm{mg} / \mathrm{kg}$ for RYR (raw material) and Monascus products, respectively (Liao et al., 2014). In European countries, standards for the maximum levels of the contaminant citrinin in food supplements are set at $2 \mathrm{mg} / \mathrm{kg}$, based on rice fermented with red yeast $M$. purpureus (European Commission No. 212/2014). Therefore, RYR produced by $M$. purpureus CMU002UXX-32-44 would be conside- 
Table 6. Summary for monacolin $\mathrm{K}$ and citrinin production, and the $\mathrm{M} / \mathrm{C}$ ratio obtained from RYR produced by parental and mutant strains

\begin{tabular}{l|c|c|c}
\hline & $\begin{array}{c}\text { Monacolin K } \\
{[\mathrm{mg} / \mathrm{kg}]}\end{array}$ & $\begin{array}{c}\text { Citrinin } \\
{[\mathrm{mg} / \mathrm{kg}]}\end{array}$ & M/C ratio \\
\hline Parental strain, M. purpureus CMU002U & $11267 \pm 278$ & $7.75 \pm 0.04$ & $1450 \pm 37$ \\
\hline $\begin{array}{l}\text { M. purpureus CMU002UXX-32-44 } \\
\text { before optimization }\end{array}$ & $1250 \pm 10$ & $0.7 \pm 0.03$ & $1790 \pm 78$ \\
after optimization & $6428 \pm 98$ & $1.61 \pm 0.02$ & $3990 \pm 79$ \\
\hline
\end{tabular}

red acceptable. It is noteworthy that the maximum citrinin content was obtained after 28 days of fermentation and decreased when the fermentation reached the optimum incubation time. This was different from the production of monacolin K. Consequently, it is recommended that RYR be harvested between days 35 and 42 of the fermentation process in order to reach an $\mathrm{M} / \mathrm{C}$ ratio of 3990. With regard to monacolin $\mathrm{K}$ and citrinin concentrations as well as the improved $\mathrm{M} / \mathrm{C}$ ratio, $M$. purpureus CMU002UXX-32-44 has been practically used in industrial-scale RYR production.

\section{Conclusions}

We have described the X-ray-induced mutation of M. purpureus CMU002U carried out to reduce citrinin production capabilities and improve the ratio of monacolin $\mathrm{K}$ to citrinin. This study is among a few research works that pertain to improving microorganisms by X-ray radiation. M. purpureus CMU002UXX-32-44 is a potential mutant strain that shows a partially improved $\mathrm{M} / \mathrm{C}$ ratio and was selected for RYR fermentation. After statistical optimization, a more improved $\mathrm{M} / \mathrm{C}$ ratio in $\mathrm{RYR}$ was obtained with an acceptable range of citrinin production according to the international standard of citrinin contamination in foods. Therefore, both the mutant strain, the optimized medium, and the relevant conditions have displayed a strong potential for application in the food industry.

\section{Acknowledgments}

The authors gratefully acknowledge the financial support provided by Chiang Mai University for a Postdoctoral Fellowship. Research findings reported in this publication have been jointly supported by the Agricultural Research Development Agency (ARDA), Thailand.

\section{References}

Babitha S., Soccol C.R., Pandey A. (2007) Solid-state fermentation for the production of Monascus pigments from jackfruit seed. Bioresour. Technol. 98: 1554-1560.
Blanc P.J., Laussac J.P., Le Bars J., Le Bars P., Loret M.O., Pareilleux A., Prome D., Prome J.C., Santerre A.L., Goma G. (1995) Characterization of monascidin A from Monascus as citrinin. Int. J. Food Microbiol. 27: 201-213.

Chairote E., Chairote G., Niamsup H., Lumyong S. (2008) The presence and the content of monacolins in red yeast rice prepared from Thai glutinous rice. World J. Microbiol. Biotechnol. 24: 3039-3047.

Chen F., Hu X. (2005) Study on red fermented rice with high concentration of monacolin $K$ and low concentration of citrinin. Int. J. Food Microbiol. 103: 331-337.

Chen M.-T., Hsu Y.-H., Wang T.-S., Chien S.-W. (2016) Mycotoxin monitoring for commercial foodstuffs in Taiwan. $\mathrm{J}$. Food Drug Anal. 24: 147-156.

Daly M.J. (2012) Death by protein damage in irradiated cells. DNA Repair 11: 12-21.

Feng Y., Shao Y., Zhou Y., Chen F. (2014) Monacolin K production by citrinin-free Monascus pilosus MS-1 and fermentation process monitoring. Eng. Life Sci. 14: 538 -545 .

Gopinath K.P., Murugesan S., Abraham J., Muthukumar K. (2009) Bacillus sp. mutant for improved biodegradation of Congo red: Random mutagenesis approach. Bioresour. Technol. 100: 6295-6300.

Jia X.Q., Xu Z.N., Zhou L.P., Sung C.K. (2010) Elimination of the mycotoxin citrinin production in the industrial important strain Monascus purpureus SM001. Metab. Eng. 12: $1-7$.

Jirasatid S., Nopharatana M., Kitsubun P., Vichitsoonthonkul T., Tongta A. (2013) Statistical optimization for Monacolin $K$ and yellow pigment production and citrinin reduction by Monascus purpureus in solid-state fermentation. J. Microbiol. Biotechnol. 23: 364-374.

Kalaivani M., Rajasekaran A. (2014) Improvement of monacolin K/citrinin production ratio in Monascus purpureus using UV mutagenesis. Nutrafoods 13: 79-84.

Kanpiengjai A., Lumyong S., Pathom-aree W., Khanongnuch C. (2014) Starchy effluent from rice noodle manufacturing process as feasible substrate for direct lactic acid production by Lactobacillus plantarum S21. J. Korean Appl. Biol. Chem. 57: 217-220.

Kanpiengjai A., Mahawan R., Lumyong S., Khanongnuch C. (2016) A soil bacterium Rhizobium borbori and its potential for citrinin-degrading application. Ann. Microbiol. 66: 807-816. 
Li Y.-P., Pan Y.-F., Zou L.-H., Xu Y., Huang Z.-B., He Q.-H. (2013) Lower citrinin production by gene disruption of ctnb involved in citrinin biosynthesis in Monascus aurantiacus Li AS3.4384. J. Agric. Food. Chem. 61: 7397-7402.

Liao C.-D., Chen Y.-C., Lin H.-Y., Chiueh L.-C., Shih D.Y.-C. (2014) Incidence of citrinin in red yeast rice and various commercial Monascus products in Taiwan from 2009 to 2012. Food Control 38: 178-183.

Miyake T., Uchitomi K., Zhang M.-Y., Kono I., Nozaki N., Sammoto H., Inagaki K. (2006) Effects of the principal nutrients on lovastatin production by Monascus pilosus. Biosci. Biotechnol. Biochem. 70: 1154-1159.

Moeller R., Raguse M., Reitz G., Okayasu R., Li Z., Klein S., Setlow P., Nicholson W.L. (2014) Resistance of Bacillus subtilis spore DNA to lethal ionizing radiation damage relies primarily on spore core components and DNA repair, with minor effects of oxygen radical detoxification. Appl. Environ. Microbiol. 80: 104-109.

Mohan Kumari H.P., Akhilender Naidu K., Vishwanatha S., Narasimhamurthy K., Vijayalakshmi G. (2009) Safety evaluation of Monascus purpureus red mould rice in albino rats. Food Chem. Toxicol. 47: 1739-1746.

Ottenheim C., Werner K.A., Zimmermann W., Wu J.C. (2015) Improved endoxylanase production and colony morphology of Aspergillus niger DSM 26641 by $\gamma$-ray induced mutagenesis. Biochem. Eng. J. 94: 9-14.

Panda B.P., Javed S., Ali M. (2010) Optimization of fermentation parameters for higher lovastatin production in red mold rice through co-culture of Monascus purpureus and Monascus ruber. Food Bioprocess Technol. 3: 373-378.

Patakova P., Branska B., Patrovsky M. (2016) Monascus secondary metabolites. [in:] Fungal Metabolites. Ed. Merillon J.-M., Ramawat K.G. Springer International Publishing, Cham: 1-31.

Prajapati V.S., Soni N., Trivedi U.B., Patel K.C. (2014) An enhancement of red pigment production by submerged culture of Monascus purpureus MTCC 410 employing statis- tical methodology. Biocatal. Agric. Biotechnol. 3: 140 -145 .

Su Y.-C., Wang J.-J., Lin T.-T., Pan T.-M. (2003) Production of the secondary metabolites $\gamma$-aminobutyric acid and monacolin $K$ by Monascus. J. Ind. Microbiol. Biotechnol. 30: 41-46.

Subsaendee T., Kitpreechavanich V., Yongsmith B. (2014) Growth, glucoamylase, pigments and monacolin K production on rice solid culture in flask and koji chamber using Monascus sp. KB9. Chiang Mai J. Sci. 41: 1044-1057.

Sun J.L., Zou X., Liu A.Y., Xiao T.F. (2011) Elevated yield of monacolin Kin Monascus purpureus by fungal elicitor and mutagenesis of UV and LiCl. Biol. Res. 44: 377-382.

Tsukahara M., Shinzato N., Tamaki Y., Namihira T., Matsui T. (2009) Red yeast rice fermentation by selected Monascus sp. with deep-red color, lovastatin production but no citrinin, and effect of temperature-shift cultivation on lovastatin production. Appl. Biochem. Biotechnol. 158: 476 -482 .

Velmurugan P., Hur H., Balachandar V., Kamala-Kannan S., Lee K.-J., Lee S.-M., Chae J.-C., Shea P.J., Oh B.-T. (2011) Monascus pigment production by solid-state fermentation with corn cob substrate. J. Biosci. Bioeng. 112: 590-594.

Wang J.-J., Lee C.-L., Pan T.-M. (2003) Improvement of monacolin $K$, $\gamma$-aminobutyric acid and citrinin production ratio as a function of environmental conditions of Monascus purpureus NTU601. J. Ind. Microbiol. Biotechnol. 30: 669-676.

Wang J.-J., Lee C.-L., Pan T.-M. (2004) Modified mutation method for screening low citrinin-producing strains of $\mathrm{Mo}$ nascus purpureus on rice culture. J. Agric. Food. Chem. 52: 6977-6982.

Wong H.-C., Bau Y.-S. (1977) Pigmentation and antibacterial activity of fast neutron-and X-ray-induced strains of Monascus purpureus Went. Plant Physiol. 60: 578-581. 